\title{
Influence of Inoculation Methods of Rhizobial Strains Having ACC-Deaminaze Activity on Growth and Yield of Rice Crop Under Salt-Affected Field
}

\author{
Muhammad Arshad Ullah' ${ }^{1 *}$, Imdad Ali Mahmood ${ }^{1}$, Arshad Ali², Muhammad Jamil' ${ }^{2}$ and Badar-uz-Zaman ${ }^{1}$ \\ ${ }^{1}$ National Agricultural Research Centre, Pakistan
}

${ }^{2}$ Soil Salinity Research Institute Pindi Bhattian, Pakistan

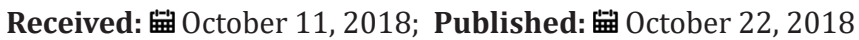

*Corresponding author: Muhammad Arshad Ullah, National Agricultural Research Centre, Park Road, Islamabad-45500, Pakistan

\begin{abstract}
A field experiment was conducted at Soil Salinity Research Institute, Pindi Bhattian, experimental farm to evaluate different Rhizobial inoculation methods on growth and yield of rice (Oryza sativa) cv. Basmati-385 under natural salt-affected soil ( $\mathrm{pH}=8.55$, $\mathrm{ECe}=5.32 \mathrm{dSm}-1$ and SAR=25.46) during 2015-16. Seeds of rice were inoculated with four rhizobial strains (RPR-32, RPR-33, MW20 (PSB) and SBCC (M8) in three ways i.e. rice seeds inoculated for direct seeding and nursery and dipping seedling roots in the solutions of these rhizobial strains. Maximum tillering was observed with all strains under different inoculation methods. Although, the strains performed better as compared to control, however, dipping of nursery roots produced significantly higher yield followed by seed inoculation for direct seeding. Overall, among all the rhizobial strains, MW-20 (PSB) and SBCC (M8) produced comparable paddy yield. The highest paddy yield $\left(291 \mathrm{gm}^{-2}\right)$ was harvested with SBCC (M8) seed inoculation which was $19 \%$ more than that of un-inoculated (control).
\end{abstract}

Keywords: Rhizobial strains (RPR-32, RPR-33, MW-20 (PSB) and SBCC); Rice; Number of tillers and Paddy yield

\section{Introduction}

Rice is a grain crop for feeding more than half of the world population [1]. The entire form of life is reliant on plants as they produce oxygen and form the staple food for humans and animals. According to report, $98 \%$ of the world's food necessities are fulfilled by 12 plant species and 14 animal species. Above $50 \%$ of the world energy ingestion is met by crops such as wheat, rice and maize [2]. Soil salinity is one of the chief abiotic factors affecting soil microbial activities and crop productivity. Reports showed that over $20 \%$ of agricultural land internationally is affected by salt [3]. It is estimated that the salinization will cause the loss of $50 \%$ arability of agricultural land by the middle of the 21st century [4]. Saline soil adversely retards the plant growth and productivity by shifting the normal metabolism of plants. Mitigation of salinity stress by plant growth promoting rhizobacteria plants. One of the effects of salt stress is an increase in the band of 1-aminocyclopropane-1carboxylic acid (ACC), a precursor of ethylene, which consequences in accretion of ethylene. Increase in the rank of ethylene away from a threshold level is termed 'stress ethylene', which minimizes plant growth [5] and alters photosynthesis and photosynthetic components [6]. Besides salt stress, other stresses such as flood, drought, wounding, pathogen attack, temperature stress, and mechanical stress also contribute to considerable rise in the level of endogenous 'stress ethylene [7].

Bio-fertilizers are defined as biologically active products or microbial inoculants of bacteria, algae and fungi (separately or in combination), which possess the innate ability either to fix or mobilize important nutrient elements from non-usable forms through biological process. Bio-fertilizers also include organic fertilizers (manure, etc.), which are rendered in an available form due to the interaction of micro-organisms or due to their association with plants. They need to be applied to soil to enhance microbial activity in the rhizosphere playing a significant role in integrated plant nutrient systems [8]. Excessive and imbalanced use of chemical fertilizers has adversely affected the soil causing decrease 
in organic carbon, reduction in microbial flora of soil, increasing acidity and alkalinity and hardening of soil. Moreover, excessive use of nitrogenous fertilizer is contaminating water bodies' thus affecting aquatic fauna and causing health hazards for human beings and animals. Hence world is shifting gradually to replace chemical fertilizers with Bio-fertilizers. Bio-fertilizers are organisms that enrich the nutrient quality of soil [9]. For many farmers, BNF is, therefore, an essential, cost effective alternative or complementary solution to industrially manufactured $\mathrm{N}$ fertilizers for staple cereal crops $[10,11]$ reported that calcium and phosphorus were limiting factors for BNF under acidic soil conditions.

In Pakistan, phosphorus in soil is generally quite abundant but it reacts readily with iron, aluminum and calcium to form insoluble compounds. These reactions result in very low phosphorus availability and low efficiency of phosphorus fertilizer used by the plants [12]. The outcome of PGPR on agricultural crops has been investigated and published by various scientists during the last two decades [13-17]. The capability of these strains for improving plant growth was tested in agriculture by using bacterial inoculation in greenhouse as well as under natural field conditions [18-20]. Ethylene is a simple, two-carbon, unsaturated hydrocarbon which is a potent regulator of plant growth and progress [21]. Initially, ethylene was known as a ripening hormone, but later demanding studies, tied with the advent of highly sophisticated analytical techniques, like gas chromatography, unveiled its role in growth and development all over the life cycle of the plant. Because of its varied and effectual role in plant growth and development, ethylene virtues equal category with other classes of plant hormones [22]. Therefore, a field experiment was conducted at Soil Salinity Research Institute, Pindi Bhattian, experimental farm to evaluate different Rhizobial inoculation methods on growth and yield of rice (Oryza sativa) cv. Basmati-385 under natural salt-affected soil.

\section{Materials and Methods}

A field experiment was conducted at Soil Salinity Research Institute, Pindi Bhattian, experimental farm to evaluate different Rhizobial inoculation methods on growth and yield of rice (Oryza sativa) cv. Basmati-385 under natural salt-affected soil $(\mathrm{pH}=8.55$, $\mathrm{ECe}=5.32 \mathrm{dS} \mathrm{m}^{-1}$ and SAR=25.46) during 2015-16. Seeds of rice were inoculated with four rhizobial strains (RPR-32, RPR-33, MW20 (PSB) and SBCC (M8) in three ways i.e. rice seeds inoculated for direct seeding and nursery and dipping seedling roots in the solutions of these rhizobial strains. Randomized complete block design was applied with three replications. The data obtained were subjected to statistical analysis using the STATISTIX statistical software (Version 8.1) and the mean values were compared using least significant difference (LSD) [23].

\section{Results and Discussion}

Table 1: Effect of inoculation methods of Rhizobial strains having ACC-Deaminaze activity on growth (plant Height, panicle length and number of tillers) of rice crop under saline environment.

\begin{tabular}{|c|c|c|c|c|c|c|c|c|c|c|c|c|c|c|c|}
\hline \multirow{2}{*}{$\begin{array}{l}\text { Inoculation } \\
\text { Methods }\end{array}$} & \multicolumn{5}{|c|}{ Plant Height (cm) } & \multicolumn{5}{|c|}{ Panicle Length (cm) } & \multicolumn{5}{|c|}{ Number of Tillers $\left(\mathrm{m}^{-2}\right)$} \\
\hline & Control & $\begin{array}{c}\text { RPR- } \\
32\end{array}$ & $\begin{array}{c}\text { RPR- } \\
33\end{array}$ & $\begin{array}{c}\text { MW-20 } \\
\text { (PSB) }\end{array}$ & $\begin{array}{l}\text { SBCC } \\
\text { (M8) }\end{array}$ & Control & $\begin{array}{c}\text { RPR- } \\
32\end{array}$ & $\begin{array}{c}\text { RPR- } \\
33\end{array}$ & $\begin{array}{c}\text { MW- } \\
20 \text { (PSB) }\end{array}$ & $\begin{array}{l}\text { SBCC } \\
\text { (M8) }\end{array}$ & Control & $\begin{array}{c}\text { RPR- } \\
32\end{array}$ & $\begin{array}{c}\text { RPR- } \\
33\end{array}$ & $\begin{array}{l}\text { MW-20 } \\
\text { (PSB) }\end{array}$ & $\begin{array}{l}\text { SBCC } \\
\text { (M8) }\end{array}$ \\
\hline M1 & 100 & 102 & 104 & 102 & 105 & 20 & 25 & 23 & 24 & 24 & $217 \mathrm{~b}$ & $220 \mathrm{~b}$ & $225 b$ & $230 \mathrm{a}$ & $235 \mathrm{a}$ \\
\hline M2 & 101 & 102 & 110 & 109 & 110 & 20 & 23 & 21 & 23 & 22 & $218 \mathrm{~b}$ & $222 b$ & $227 \mathrm{ab}$ & $233 a$ & $238 \mathrm{a}$ \\
\hline M3 & 102 & 110 & 115 & 117 & 111 & 19 & 24 & 22 & 25 & 23 & $219 b$ & $225 b$ & $230 \mathrm{a}$ & $239 a$ & $245 a$ \\
\hline LSD & NS & & & & & NS & & & & & 17 & & & & \\
\hline
\end{tabular}

Values followed by same letter(s) are statistically similar at $\mathrm{P}=0.05$ level of significance.

Growth parameters (plant height, panicle length and tillering) data was represented in Table 1. Plant height and panicle length showed non- significant results among three inoculation methods. However, all the inoculation methods exhibited better performance than control i.e. without-inoculation.MW-20(PSB) attained the highest plant height $(117 \mathrm{~cm})$ in seedling root dipping inoculation methods. Similar trend was also predicted in panicle length. Significant results were indicated regarding tillering of the rice plants. SBCC (M8) rhizobial got maximum number of tillers $\mathrm{m}^{-2}$ (245) among other rhizobial strains, Seedling root dipping technique was the best inoculation method than other two methods. Maximum tillering was observed with all strains under different inoculation methods [24] investigated that biozote significantly affected on germination, root length, fresh weight and dry weight in all mung bean varieties [25] concludes that growth of maize plants behaves better under saline environment as inoculated with different rhizobial strain showing ACC Deaminaze activity due to the production of ethylene under stressed conditions. Reduction in sodium uptake by the utilization of different rhizobial strains under saline environment is a positive sign to induce salt tolerance biologically. Data regarding 1000- grain weight and grain yield indicated in Table 2 Non- significant results were attained in 1000grain weight among inoculation methods as well as rhizobial strains. But three inoculation methods performed better than control. SBCC (M8) rhizobial strain produced the highest 1000- grin weight (25g) among other strains under seedling root dipping inoculation method [26] resulted that growth of wheat plants performed better under saline environment as inoculated with different rhizobial strains due to the production of ethylene under stressed conditions. 
Table 2: Effect of inoculation methods of Rhizobial strains having ACC-Deaminaze activity on1000- grain weight and yield of rice crop under saline environment.

\begin{tabular}{|c|c|c|c|c|c|c|c|c|c|c|}
\hline $\begin{array}{c}\text { Inoculation } \\
\text { Methods }\end{array}$ & \multicolumn{4}{|c|}{ 1000-Grain Weight (g) } & \multicolumn{4}{c|}{ Grain Yield (g.m-2 } \\
\hline & Control & RPR-32 & RPR-33 & MW-20(PSB) & SBCC (M8) & Control & RPR-32 & RPR-33 & MW-20(PSB) & SBCC (M8) \\
\hline M1 & 14 & 17 & 19 & 19 & 22 & $245 \mathrm{bc}$ & $255 \mathrm{~b}$ & $261 \mathrm{~b}$ & $265 \mathrm{~b}$ & $271 \mathrm{ab}$ \\
\hline M2 & 15 & 18 & 19 & 20 & 23 & $246 \mathrm{bc}$ & $257 \mathrm{~b}$ & $260 \mathrm{~b}$ & $277 \mathrm{a}$ & $263 \mathrm{~b}$ \\
\hline M3 & 15 & 22 & 24 & 24 & 25 & $244 \mathrm{bc}$ & $266 \mathrm{~b}$ & $272 \mathrm{a}$ & $280 \mathrm{a}$ & $291 \mathrm{a}$ \\
\hline LSD & NS & & & & & 20 & & & & \\
\hline
\end{tabular}

M1 = Seed Inoculation for DSR M2 = Nursery Seed Inoculation M3 = Seedling Root Dipping Values followed by same letter(s) are statistically similar at $\mathrm{P}=0.05$ level of significance.

Although, the strains performed better as compared to control, however, dipping of nursery roots produced significantly higher yield followed by seed inoculation for direct seeding. Overall, among all the rhizobial strains, MW-20 (PSB) and SBCC (M8) produced comparable paddy yield. The highest paddy yield $\left(291 \mathrm{gm}^{-2}\right)$ was harvested with SBCC (M8) seed inoculation which was 19\% more than that of un-inoculated (control) [27] reported the reduction in sodium uptake by the utilization of different rhizobial strains having ACC deaminaze activity under saline environment is an encouraging sign to induce salt tolerance naturally and reduce the toxic effects of utilization of chemicals for reclamation of salt - affected lands.

\section{Conclusion}

This study concluded that maximum tillering was observed with all strains under different inoculation methods. Although, the strains performed better as compared to control, however, dipping of nursery roots produced significantly higher yield followed by seed inoculation for direct seeding. Overall, among all the rhizobial strains, MW-20 (PSB) and SBCC (M8) produced comparable paddy yield. The highest paddy yield $\left(291 \mathrm{gm}^{-2}\right)$ was harvested with SBCC (M8) seed inoculation which was 19\% more than that of uninoculated (control).

\section{References}

1. Fageria NK, Santos AB, Cutrim VA (2008) Dry matter and yield of lowland rice genotypes as influenced by nitrogen fertilization. Journal of Plant Nutrition 31: 788-795.

2. Thrupp LA (2000) Linking agricultural biodiversity and food security: the valuable role of agrobiodiversity for sustainable agriculture. International affairs 76(2): 283-297.

3. Pitman MG, Läuchli A (2002) Global impact of salinity and agricultural ecosystems. Salinity: environment plantsmolecules pp. 3-20.

4. Wang, WX, Barak T, Vinocur B, Shoseyov O, Altman A (2003) Abiotic resistance and chaperones: possible physiological role of SP1, a stable and stabilizing protein from Populus. In Plant Biotechnology and Beyond pp. 439-443.

5. Penrose DM, Glick BR (2003) Methods for isolating and characterizing Accdeaminase containing plant growth promoting rhizobacteria. Physiol Plant 118: 10-15.
6. Koryo HW (2006) Effect of salinity on growth, photosynthesis and solute composition of the potential cash crop halophyte plantago. Environ Exp Bot 56(2): 136-146.

7. Stearns, J and Glick BR (2003) Transgenic plants with altered ethylene biosynthesis or perception. Biotechnol Adv 21(3): 193-210.

8. Solaiman ARM, MG Rabbani (2005) Effects of Rhizobium inoculant and Nitrogen Application of Pea. Bangladesh J Microbiol 21(1): 36-40.

9. Bent E, Tuzun, S, Chanway CP, Enebak S (2001) Alterations in plant growth and in root hormone levels of lodge pole pines inoculated with rhizobacteria. Can J Microbiol 47(9): 793-800.

10. Carlsson G, Huss Danell K (2003) Nitrogen fixation in perennial forage legumes in the field. Plant and Soil 253(2): 353-372.

11. Waluyo SH, An LT, Mannetje L (2004) Effect of phosphate on nodule primordia of soybean (Glycine max L. Merrill) in acid soils in rhizotron experiments. Indonesian Journal of Agricultural Science 5(2): 37-44.

12. Jodie NH, BN Peter (2000) Selection of phosphate solubilizers for use as biofertilizers.8th international symposium on nitrogen fixation with non legumes. December 3-7, 2000. (Eds.) Ivan Kennedy and Les Copeland. The University of Sydney Australia pp. 115.

13. Asghar, HN, Zahir ZA, \& Arshad, M (2004) Screening rhizobacteria for improving the growth, yield, and oil content of canola (Brassica napus L). Aust J Agric Res 55(2): 187-194.

14. Asghar HN, Zahir ZA, Arshad M, Khaliq A (2002) Relationship between in vitro production of auxins by rhizobacteria and their growth promoting activities in Brassica juncea. L Biol Fertil Soils 35(4): 231-237.

15. Khalid A, Arshad M, Zahir ZA (2003) Growth and yield response of wheat to inoculation with auxin producing plant growth promoting rhizobacteria Pak J Bot 35(4): 483-498.

16. Khalid, A, Arshad, M, Zahir ZA (2004) Screening plant growth promoting rhizobacteria for improving growth and yield of wheat. J Appl Microbiol 96(3): 473-480.

17. Zahir ZA, Arshad M, Frankenberger WT (2004) Plant growth promoting rhizobacteria: Applications and perspectives in agriculture. Adv Agron 81: $97-168$

18. Salamone IEG (2000) Direct beneficial effects of cytokinin producing rhizobacteria on plant growth. Ph.D. Thesis, University of Saskatchewan, Saskatoon, SK Canada.

19. Shaharoona B, Jamro GM, Zahir ZA, Arshad, M, Memon KS (2007) Effectiveness of various Pseudomonas spp., and Burkholderiacaryophylli containing ACC-deaminase for improving growth and yield of wheat (Triticum aestivum L.) J Microbiol Biotechnol 17(8): 1300-1307.

20. Shaharoona B, Naveed M, Arshad M, and Zahir ZA (2008) Fertilizer dependent efficiency of Pseudomonads for improving growth, yield, and nutrient use efficiency of wheat (Triticum aestivum L). Appl. Microbiol Biotechnol 79(1): 147- 155. 
21. Binder BM (2008) The ethylene receptors: Complex perception for a simple gas. Plant Sci 75: 8-17.

22. Arshad M, Frakenberger WT (2002) Ethylene: Agricultural Sources and Applications. Kluwer, Academic Publishers, New York, 90(3): 424.

23. Steel RGD, Torrie JH (1997) Principles and Procedure of Statistics. McGraw Hill Book Co, Inc. Singapore pp. 173-177.

24. Ullah MA, Baber R, Hyder SI, Sultan T, Mahmood IA et al. (2016) Effect of Rhizobium on growth of different Mungbean varieties under salt stress conditions. International Invention Journal of Agricultural and Soil Science 4(4): 44-46.

25. Arshadullah M, Ali A, Hyder SI, Sultan T Nazeer A (2017) Efficacy of Plant Growth Promoting Rhizobacteria Containing Acc-Deaminase
Activity for Enhancing Growth of Maize (Zea Mays L) under Salt-Stressed Conditions. International Journal of Research Studies in Agricultural Sciences 3(7): 23-29.

26. Arshadullah M, Hyder SI, Mahmood IA, Sultan T, Naveed S (2017) Mitigation of salt stress in wheat plant (Triticum aestivum) by plant growth promoting rhizobacteria for ACC Deaminase. ASJ: International Journal of Agricultural Research, Sustainability, and Food Sufficiency $4(6): 160-164$

27. Arshadullah M, Hyder SI, Baber R and Sultan T (2017) Screening Rhizobacteria containing Acc-Deaminase for Growth and Yield of Rice (Oryza sativa) under Salt Stress Conditions International Journal of Plant Breeding and Crop Science 4(2): 251-255.

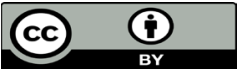

This work is licensed under Creative Commons Attribution 4.0 License

To Submit Your Article Click Here:

Submit Article

DOI: 10.32474/CIACR.2018.05.000202

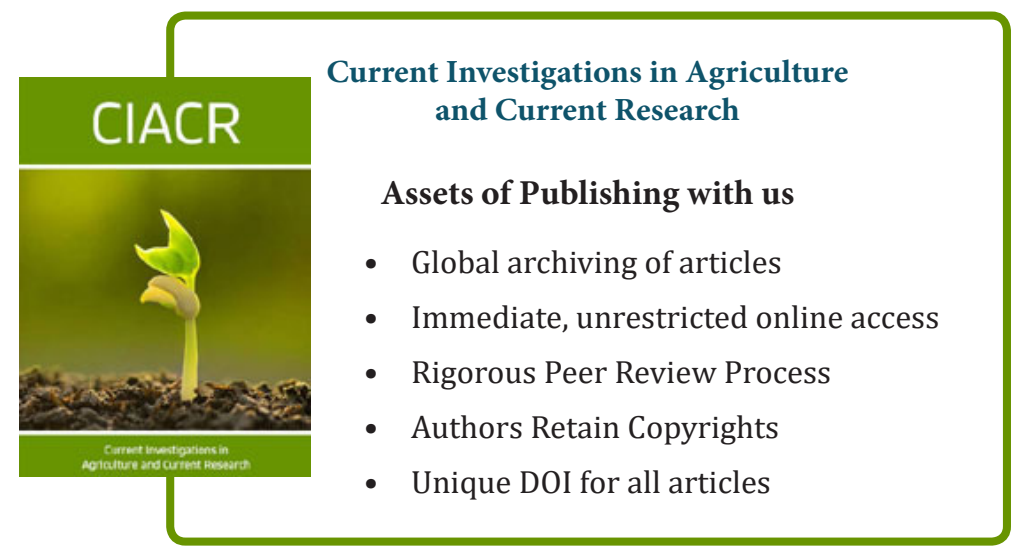

